\title{
Sputum and ciliary inhibition in asthma
}

\author{
MAURICIO J DULFANO, CHUN KA LUK
}

\begin{abstract}
From the Respiratory Care Center and Sputum Laboratory, Veterans Administration Medical Center, Brooklyn, New York
\end{abstract}

ABSTRACT Twenty-eight sputum samples collected from 20 patients with chronic bronchial asthma of atopic and intrinsic clinical types were incubated with human bronchial explants to study their influence on ciliary motility. Of these, $19(68 \%)$ of the sputa exerted a ciliary inhibitory effect of varying degree in a two-hour period. Analysis of the data indicates that (1) the ciliary inhibitory effect was invariably present when patients produced a distinctive slurry sputum; (2) this occurred more frequently during clinical exacerbations; (3) the induced ciliary inhibition was reversible on removal of the sputum; (4) the intensity of the ciliary inhibitory effect decreased with clinical improvement of the patient; (5) the inhibitory effect was unrelated to the medications used; (6) it was equally common in the atopic and the intrinsic types of asthmatic patients; (7) the effect was not $\mathrm{pH}$ dependent or related to the degree of eosinophilia. The ciliary inhibitory factor in sputum was identified as having a molecular weight of 6000-8000. It may play a part in the pathogenesis of asthma and recognition of sputum containing it carries implications for treatment.

Recent studies suggest that certain human fluids may modulate ciliary beating frequency in tissues from lower animal species and mammals. A ciliary dyskinesia factor has been reported in the serum of patients with cystic fibrosis, ${ }^{1}$ various respiratory and autoimmune diseases, ${ }^{2}$ and asthma. ${ }^{3}$ This factor was demonstrated by biological assays in oyster gills ${ }^{45}$ and rabbit trachea. ${ }^{26-8}$ Wilson and Fudenberg found specific biochemical differences between the ciliary dyskinesia factor in serum from patients with cystic fibrosis and that from asthmatic patients. ${ }^{3}$ Others, however, have noted that human sera from both normal people and patients with cystic fibrosis could induce cytolysis of the mucosal surface in rabbits. $^{68}$ These observations suggested that species incompatibility may be responsible for tissue damage, which then leads to ciliary dysfunction. Recently, Gleich and his colleagues, pursuing longterm studies with a major basic protein isolated from eosinophils of asthmatic patients, found it capable of inducing ciliostasis, cytolysis, and exudation in man and pig. ${ }^{10}$ This major basic protein is present in large quantities in asthmatic patients.

Studies in our laboratory have shown that sputum from some asthmatic patients can produce ciliary inhibitory effects when incubated with strips of frog

Address for reprint requests: Dr MJ Dulfano, Respiratory Care Center and Sputum Laboratory, Veterans Administration Medical Center, Brooklyn, New York 11209, USA. palate mucosa. ${ }^{112}$ This effect was not accompanied by anatomical disruption of the mucosa and was reversible. The present study was undertaken to determine whether sputum from patients with asthma would have the same ciliostatic effect on explants of human bronchial mucosa.

\section{Methods}

THE SUBSTRATUM

After informed consent had been given, biopsy specimens of bronchial mucosa were obtained in the course of routine diagnostic fibreoptic bronchoscopies of patients with various respiratory diseases. The biopsy site was an area of mucosa that appeared normal by visual examination. Previous experience with this technique assured satisfactory results and no significant differences in ciliary activity from various bronchial areas. ${ }^{13}$ Immediately on removal the explant, which was to be used as substratum for bioassay, was placed in tubes containing culture medium 199 (Gibco, NY) and the mixture was incubated at $37^{\circ} \mathrm{C}$ for half an hour to an hour before the test.

\section{THE SPUTUM}

The sputum to be tested came from 20 patients suffering from chronic bronchial asthma. ${ }^{14}$ Clinically, the group included 10 patients with "atopic" asthma 
Table 1 Clinical and physiological data on the 20 asthmatic patients studied

\begin{tabular}{|c|c|c|c|c|c|c|c|c|c|c|c|c|}
\hline \multirow{3}{*}{$\begin{array}{l}\text { Sputum* } \\
\text { donor }\end{array}$} & \multirow{3}{*}{$\begin{array}{l}\text { Clinical } \\
\text { type } \dagger\end{array}$} & \multirow{3}{*}{$\begin{array}{l}\text { Steroid } \\
\text { treatment }\end{array}$} & \multicolumn{5}{|c|}{ Clinically worse } & \multicolumn{5}{|c|}{ Clinically better } \\
\hline & & & \multirow[t]{2}{*}{$\overline{F E V_{1} \ddagger}$} & \multicolumn{4}{|c|}{ Sputum cytology** } & \multirow[t]{2}{*}{$F E V_{1} \ddagger$} & \multicolumn{4}{|c|}{ Sputum cytology ${ }^{* *}$} \\
\hline & & & & $E$ & $P$ & $H$ & $B E p$ & & $E$ & $P$ & $H$ & $B E_{p}$ \\
\hline 1 & I & + & $15 / 29$ & 65 & 10 & 17 & 8 & $40 / 55$ & 10 & 27 & 35 & 28 \\
\hline 2 & I & + & $25 / 36$ & 82 & 6 & 5 & 7 & $43 / 69$ & 38 & 22 & 7 & 33 \\
\hline 3 & A & + & $66 / 80$ & 64 & 21 & 7 & 8 & $63 / 80$ & 15 & 56 & 14 & 15 \\
\hline 4 & A & + & $45 / 55$ & 61 & 19 & 10 & 10 & $48 / 55$ & 22 & 58 & 15 & 5 \\
\hline 5 & A & + & $35 / 39$ & 48 & 36 & 12 & 4 & $50 / 62$ & 3 & 52 & 21 & 24 \\
\hline 6 & 1 & + & $31 / 34$ & 55 & 26 & 9 & 10 & $31 / 40$ & 37 & 20 & 18 & 25 \\
\hline 7 & I & + & $31 / 35$ & 72 & 8 & 14 & 6 & $31 / 39$ & 33 & 12 & 35 & 20 \\
\hline 8 & I & + & $43 / 43$ & 70 & 15 & 7 & 8 & $46 / 52$ & 30 & 14 & 15 & 41 \\
\hline$\ddot{q}$ & A & + & $30 / 36$ & 67 & 20 & 7 & 6 & $39 / 51$ & 10 & 40 & 28 & 22 \\
\hline 10 & I & + & $59 / 66$ & 45 & 28 & 19 & 8 & - & 17 & 21 & 15 & 47 \\
\hline 11 & I & + & $18 / 24$ & 59 & 19 & 14 & 8 & $32 / 37$ & 11 & 31 & 22 & 36 \\
\hline 12 & A & + & $10 / 22$ & 53 & 28 & 12 & 7 & $40 / 53$ & - & - & - & - \\
\hline 13 & I & + & $25 / 36$ & 54 & 21 & 15 & 10 & $50 / 62$ & 25 & 46 & 11 & 18 \\
\hline 14 & I & - & $39 / 45$ & 69 & 13 & 8 & 10 & $45 / 52$ & 11 & 25 & 46 & 18 \\
\hline 15 & A & - & $40 / 42$ & 45 & 30 & 9 & 16 & $60 / 68$ & 56 & 10 & 25 & 9 \\
\hline 16 & A & + & $42 / 54$ & 47 & 14 & 26 & 13 & $61 / 64$ & 45 & 16 & 33 & 6 \\
\hline 17 & A & + & $13 / 19$ & 62 & 20 & 9 & 9 & $19 / 27$ & 9 & 78 & 5 & 8 \\
\hline 18 & A & + & $38 / 38$ & 73 & 9 & 7 & 11 & $57 / 73$ & 25 & 48 & 9 & 18 \\
\hline 19 & A & + & $38 / 38$ & 53 & 10 & 26 & 11 & $46 / 54$ & 8 & 34 & 37 & 21 \\
\hline 20 & I & + & $45 / 48$ & 81 & 10 & 3 & 6 & $68 / 80$ & 57 & 10 & 25 & 8 \\
\hline
\end{tabular}

"Nos 1-8 studied during both "worse" and "better" periods; 9-14 during "worse" periods only; and 15-20 during "better" periods only (see text).

†A - atopic; I - intrinsic.

$\ddagger$ Percentage of predicted values before/after bronchodilator aerosol.

${ }^{* *} \mathrm{E}$ - eosinophil; $\mathrm{P}$ - polymorphonuclear leucocyte; $\mathrm{H}$ - histiocyte; $\mathrm{BEp}$ - bronchial epithelial cells (figures are percentages of total white blood cell count)

and 10 with the "intrinsic" variety (table 1 ). In addition to having the expected symptoms and signs they all had airflow obstruction, which at some time had been partially reversible by administration of bronchodilators or steroids.

Since the degree of clinical exacerbation at a given moment is difficult to express for an individual asthmatic patient, we decided to classify the patients into two broad categories, "worse" and "better." This indicated for each individual the extent of his relative clinical severity at the time of the collection of the sample ${ }^{15}$ (table 1). An attempt was made to collect and test the sputum of these patients at both the "worse" and the "better" clinical stages. Some of the collected sputa, however, could not be tested for the presence of ciliary inhibitory effect either because bronchoscopic explants were not available on the same day or because the $\mathrm{pH}$ of the sputum was unsuitable $(\leqslant 6.5$ or $\geqslant 9.6)$.

The sputum was collected in the early morning at room temperature. Gram stain and Papanicolaou smears were prepared from each sample to ascertain the degree of purulence and site of origin in the lower respiratory tract (table 1). The samples were centrifuged at $30000 \mathrm{~g}$ in an IEC B-20A refrigerated centrifuge for 45 minutes; this yields a viscous pellet and a "sol" layer. The gel pellet was discarded and the sol used to study the effects on the ciliary activity of the mucosa. The $\mathrm{pH}$ of the sputum sol was measured with a Beckman model SS-2 pH meter at $24^{\circ} \mathrm{C}$. All samples with a $\mathrm{pH}$ less than 6.5 were excluded from analysis in view of the findings of Holma et al that in bovine trachea ciliary inhibition develops at $\mathrm{pH} \leqslant 6 \cdot 5$ or $\geqslant 9 \cdot 6 .^{16}$

\section{CILIARY BIOASSAY}

The bronchial explant was placed in a flat-bottomed, welled slide of Fisher-Littman type containing Medium 199, and kept at $37^{\circ} \mathrm{C}$ by air curtain incubator. Ciliary beating frequency was measured with a photoelectric system developed in this laboratory. ${ }^{13}$ The actual field scanned by the photomultiplier is about $30 \mu \mathrm{m}$ at $\times 200$ magnification. The number of deflections per second are recorded as ciliary beating frequency. ${ }^{13}$ Under these conditions our control ciliary beating frequency values in the explant are $12.7 \pm 1.3$ in Medium 199 and 13.8 $\pm 1 \cdot 3$ in buffered saline with $\mathrm{pH} 7 \cdot 2$. Over a twohour period these values remain within $10 \%$ of initial ciliary beating frequency values.

After we had obtained normal control ciliary beating frequency values (10-16 beats a second) ${ }^{17}$ Medium 199 was carefully aspirated from the well with filter paper and replaced with sputum sol, care being taken not to disturb the underlying tissue. Thus ciliary beating frequency could be measured repeatedly in the same area of the explant. The presence of a ciliary inhibitory effect was accepted only if the ciliary beating frequency was decreased by $25 \%$ or more from the control value within two 
Table 2 Consistency of ciliary inhibitory effect of sputum in different explants

\begin{tabular}{lll}
\hline Source of sputum & Source of explant & $\begin{array}{l}\text { Ciliary inhibition } \\
(\%)\end{array}$ \\
\hline JO & VO & 100 \\
& VT & 100 \\
GJ & JN & 100 \\
& CD & 100 \\
JT & PV & 36 \\
& MC & 34 \\
ON & ZR & 55 \\
& NB & 56 \\
VO & MR & 31 \\
& CA & 48 \\
FO & MG & 100 \\
& KO & 100 \\
VT & BW & 100 \\
& VV & 100 \\
FJ & CJ & 100 \\
& HJ & 30 \\
\hline
\end{tabular}

hours of incubation with the sputum sol.

To further minimise experimental artefacts additional precautions were taken. (1) Each ciliary beating frequency value was the average of 10 consecutive readings of acceptable quality. (2) To test the reversibility of the ciliary inhibitory effect in each case, where a significant decrease of ciliary beating frequency took place the sputum sol was replaced with Medium 199 until control values were restored. (3) Eight sputum sols with a demonstrated ciliary inhibitory effect were again tested on different explants, obtained from new donors, on different days. The presence of a ciliary inhibitory effect was repeatedly confirmed, with only minor differences in degree of inhibition (table 2). (4) Five explants were exposed to sputum samples with and without the ciliary inhibitory factor. The test showed that each explant was capable of yielding the correct positive or negative response to each sputum sol (table 3 ).

Table 3 Specificity of explant response to sputum ciliary inhibitory effect

\begin{tabular}{llc}
\hline Source of explant & Source of sputum & $\begin{array}{c}\text { Ciliary inhibition } \\
(\%)\end{array}$ \\
\hline MC & JO & 34 \\
& SL & 7 \\
MR & HW & 13 \\
& KA & 28 \\
VO2 & 29 \\
SA & BP & 8 \\
& KT & 100 \\
& BJ & 44 \\
EJ & ON & 100 \\
& KO & 100 \\
VV & KF & 26 \\
& RR & 0 \\
& WA & 53 \\
& VO1 & 100 \\
\hline
\end{tabular}

Table 4 Dose-response relationship of ciliary inhibitory effect (CIE)

\begin{tabular}{|c|c|c|}
\hline $\begin{array}{l}\text { CIE containing } \\
\text { fraction } \\
\text { concentration } \\
(\%)\end{array}$ & $\begin{array}{l}\text { Degree of inhibition } \\
\text { (\%) }\end{array}$ & $\begin{array}{l}\text { Time of } \\
\text { appearance ( } \mathrm{min})\end{array}$ \\
\hline $\begin{array}{r}100 \\
50 \\
25 \\
16\end{array}$ & $\begin{array}{r}100 \\
100 \\
30 \\
15\end{array}$ & $\begin{array}{l}20 \\
60 \\
60 \\
60\end{array}$ \\
\hline
\end{tabular}

Preliminary experiments were carried out to characterise the nature of the material responsible ic for the ciliary inhibitory effect. Sputum sols were subjected to gel chromatography fractionation on $\vec{\sigma}$ Sephadex G-200 and G-50. The fractionation was 으 done on several batches of sputum in which the cili- ary inhibitory effect was known to be present or $\mathcal{D}$ absent. Fractions were pooled into six groups. Each $\frac{\mathbb{}}{0}$ group's pool was concentrated and assayed for the $\frac{\mathbb{D}}{3}$ ciliary inhibitory effect by the method described above for single sol speciments. In addition, the frac- $\stackrel{\mathbb{1}}{-}$ tion containing ciliary inhibitory effect was diluted $\vec{\oplus}$ with isotonic sodium chloride to various concentra- $N$ tions and a dose-response effect was elicited (table 4).

Bronchial explants were prepared for scanning electron microscopy within two hours after a ciliary inhibitory effect had been demonstrated. This was to $\frac{D}{D}$ determine whether the observed effect resulted $\stackrel{\varrho}{\rightleftharpoons}$ from histological damage to the mucosa with secondary entrapment of the cilia.

\section{Results}

Twenty-eight sputum samples from the 20 patients $\frac{0}{0}$ were tested for effects on ciliary activity. On gross $\underset{-}{-}$ examination the tested sputa appeared to be of two 3 kinds, one being of the well-known mucoid type and the other appearing as a more liquid material some- $\frac{\rho}{3}$ what resembling the secretions of allergic rhinitis. This slurry type of sputum was seen more frequently during the periods of clinical exacerbation of $\frac{D}{O}$ asthma. ${ }^{1215}$ Of the 28 sputum samples, 14 were of the slurry type and 14 of the mucoid variety. No $N$ purulent samples were produced. During the $N$ "worse" clinical phase, 10 patients produced slurry expectorates and four produced mucoid sputa, $\omega$ whereas during the "better" clinical period there were 10 mucoid and four slurry samples (table 5). Nineteen of the 28 sputum sols (68\%) prepared from the collected samples inhibited ciliary activity. Examination of the data showed no correlation between ciliary inhibitory effect and the clinical type of $\frac{}{\pi}$ asthma (intrinsic or atopic).

All the "slurry" sputum samples induced a ciliary 
Table 5 Ciliary inhibitory effect (CIE), clinical state, and sputum type

\begin{tabular}{llc}
\hline & \multicolumn{2}{l}{$\begin{array}{l}\text { Total number of samples } \\
\text { (number with CIE) }\end{array}$} \\
\cline { 2 - 3 } & "Worse" & "Better" \\
\hline Slurry & $10(10)$ & $4(4)$ \\
Mucoid & $4(1)$ & $10(4)$ \\
\hline
\end{tabular}

inhibitory effect, whereas this effect was observed in only five of the 14 mucoid sputum samples. The difference is statistically significant by the Fisher probability test $(p<0.003)$. Although the ciliary inhibitory effect was seen more frequently during the "worse" clinical periods, the difference was not statistically significant $(p<0 \cdot 16)$ (table 5). The relation between clinical activity of disease and the presence of a ciliary inhibitory effect in the sputum was examined in seven patients whose clinical condition changed from "worse" to "better". In all cases the ciliary inhibitory effect disappeared or diminished with clinical improvement (table 6). The presence of the inhibitory effect was not related to the type or amount of medication (including steroids).

As the onset of an asthmatic exacerbation in untreated patients generally coincides with an increase of eosinophils, we sought a correlation between sputum eosinophilia and percentage of ciliary inhibition. This could not be shown statistically $(\mathrm{r}=0 \cdot 2)$.

The $\mathrm{pH}$ of the sputum samples ranged from 6.5 to $9 \cdot 0$, most values being in the range $6 \cdot 8-8 \cdot 0$. From 6.5 to 9.0 no direct correlation between $\mathrm{pH}$ and degree of ciliary inhibition was found $(r=0 \cdot 15)$ (fig 1).

In every case ciliary inhibition was reversed after substitution of Medium 199 for the sputum sol. Ultrastructural studies using scanning and transmission electron microscopy failed to show signs of cell damage on the bronchial mucosa.

Fractionation of sputum sols containing the ciliary inhibitory factor on Sephadex G-200 and G-50 indi-

Table 6 Sputum ciliary inhibitory effect and clinical changes*

\begin{tabular}{llcc}
\hline Patient & Diagnosis & \multicolumn{2}{c}{ Ciliary inhibition (\%) } \\
\cline { 3 - 4 } & & "Worse" & “Better" \\
\hline AA & Intrinsic asthma & 49 & 17 \\
ON & Intrinsic asthma & 100 & 42 \\
PM & Intrinsic asthma & 80 & 5 \\
FJ & Intrinsic asthma & 100 & 37 \\
EI & Atopic asthma & 54 & 30 \\
GJ & Atopic asthma & 100 & 27 \\
NJ & Atopic asthma & 64 & 33 \\
\hline
\end{tabular}

*." Worse" and "better" indicate relative degree of clinical severity of asthma for each patient.

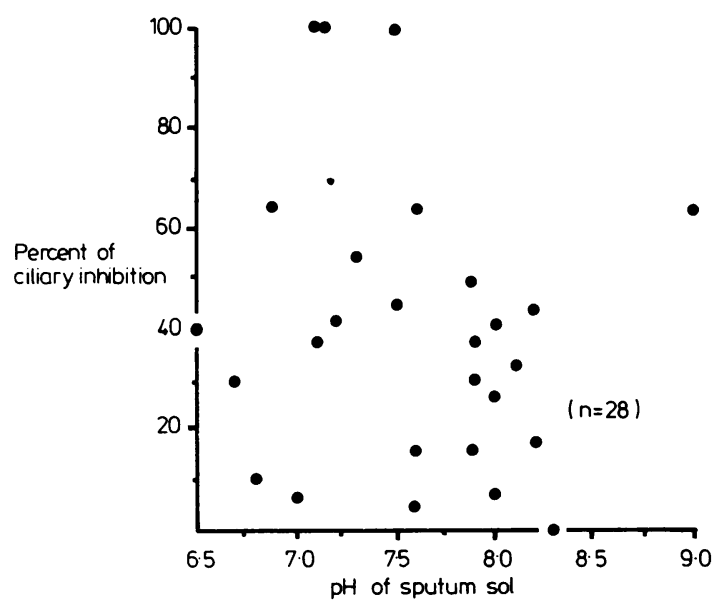

Fig 1 pH and degree of ciliary inhibitory effect of 28 sputum samples from asthmatic patients.

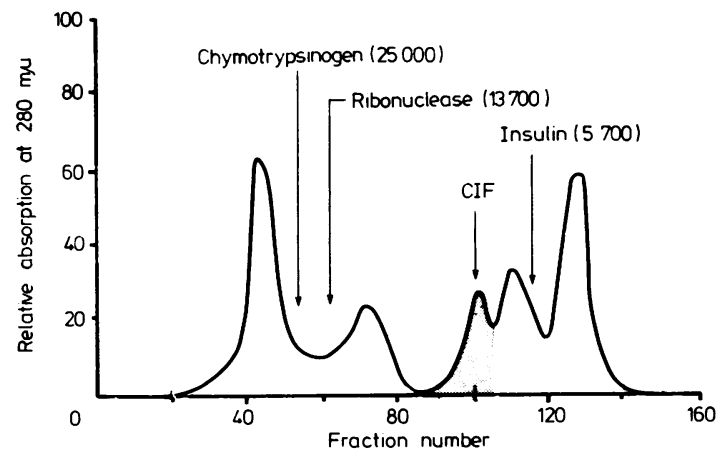

Fig 2 Chromatogram of sputum sol containing ciliary inhibitory factor (CIF) (Sephadex G-50 in phosphate buffered saline, $p H=7 \cdot 2 ; 5 \times 90 \mathrm{~cm}$ column).

cated that the inhibitory effect was found predominantly in fractions with a molecular weight of 6000 9000 (fig 2).

\section{Discussion}

The results of this study suggest that the ciliary inhibitory effect results from a specific interaction between a substance sometimes present in the sputum of some asthmatic patients and the cilia of the human bronchial mucosa. This confirms the results of earlier studies by our group ${ }^{11} 12$ in which frog palates were used as substrate. The ciliary impairment does not result from lack of nutrients in the medium. This ciliary inhibitory effect appears to be a functional phenomenon not secondary to structural damage to the cilia or mucosal cells and it is 
reversible. The functional nature of the inhibitory effect was also expressed in clinical terms, by the decrease or total disappearance of the ciliary inhibition after the amelioration of symptoms seen in some patients. These characteristics are different from the ciliotoxic effects reported to be produced by serum from patients with cystic fibrosis in lower species of animals. ${ }^{1-8}$ The differences may be real or be related to the method of testing. ${ }^{68}$

Differences in reported results may be related to whether serum or respiratory secretions are studied. In our study, where sputum and blood samples were obtained from our asthmatic patients at the same time inhibition of ciliary activity was detected only in the sputum.

Frigas and colleagues, in comprehensive work dealing with the major basic protein of the eosinophil, have reported the presence of a protein with a molecular weight of about 9000 in the blood and sputum of asthmatic patients capable of inducing mucosal desquamation and cytolysis as well as ciliary inhibition in bronchial explants of man and guinea-pig. ${ }^{10}$ They have also reported that this major basic protein is present in much higher quantities in the sputum of asthmatic patients than in the sputum from patients with other respiratory disease. ${ }^{9}$ In our studies gel fractionation of sputum containing the ciliary inhibitory factor on Sephadex G-200 and G-50 points to a protein of similar molecular weight. But radioimmunoassays of our sputum fractions containing ciliary inhibitory factor performed in Dr Frigas's laboratory at the Mayo Clinic were negative for major basic protein and bioassays of their material containing major basic protein performed in our laboratory failed to inhibit human cilia (personal communications). This leaves open the question of whether major basic protein and the ciliary inhibitory factor we describe are identical. Possibly large-molecular-weight proteins carrying the inhibitory factor break down into smaller complexes and these may then appear in more than one analytical fraction. This might also be the case with the ciliary dyskinesia factor that Wilson and Fudenberg found in sera of asthmatic patients. ${ }^{3}$ This was identified as a very-high-molecular-weight protein, which was different from the ciliary dyskinesia factor that they found in serum of patients with cystic fibrosis. The mechanism of action of the ciliary inhibitory effect remains uncertain. In our material the effect appeared to be purely functional, affecting only ciliary dynamics, whereas the major basic protein of Gleich and his colleagues seems to induce ciliary inhibition in the context of a wider effect on the mucosa characterised by desquamation and cytolysis. ${ }^{10}$

Holma et $\mathrm{l}^{16}$ found that at $\mathrm{pH} \leqslant 6.5$ or $\geqslant 9.6$ there is ciliary inhibition. Careful examination of the relation between $\mathrm{pH}$ and ciliary activity, however, in all our samples with a $\mathrm{pH}$ in the range $6 \cdot 5-9 \cdot 0$ indicated no significant correlation. This conclusion is supported by a recent study in our laboratory showing that human cilia develop the highest ciliary beating frequency in the $\mathrm{pH}$ range $6 \cdot 5-8 \cdot 0 .{ }^{18}$

The results of this study and our previous observations $^{1112}$ suggest that the ciliary inhibitory effect in the sputum of asthmatic patients occurs more frequently during acute or subacute clinical exacerbations than during stable periods, and that the sputum produced during exacerbations (slurry sputum) frequently differs in appearance from that produced during clinical remissions (mucoid sputum). We followed for two years the ciliary inhibitory activity in the sputum of an asthmatic patient on continuous steroid treatment and observed such "waxing" and "waning" of the inhibitory activity with clinical and spirometric variations. Interestingly, sputum from this patient induced complete inhibition of ciliary activity whereas his serum, tested simultaneously, failed to affect ciliary beating on a control assay.

Previous investigators have noted the association between slurry sputum and asthma, and labelled the production of such sputum bronchorrhoea. ${ }^{1920}$ Some years ago we became interested in this sputum and reported that when placed in contact with ciliated mucosa (from the frog) it was transported at a very slow rate or not at all. ${ }^{15}$ Thus recognition of this type of sputum has clinical significance since it always indicates, in asthmatic patients, the presence of the ciliary inhibitory factor and its potential consequences.

A decrease in mucociliary transport in asthmatic patients has been reported by several investigators. $^{2122}$ We do not know whether this results from the special rheological characteristics of the mucus in asthmatic patients (very low viscosity and elastic modulus). the currently described ciliary inhibitory effect, or both. Clearly, the rheological characteristics, though they greatly influence the rate of transport of sputum by ciliated mucosa, ${ }^{23}$ could not explain the ciliary inhibitory effect since the sol fraction of sputum was used and the viscoelastic properties of these sols is uniformly low. O

All these considerations led us to form the $N$ hypothesis that in asthmatic patients a functional $\mathrm{N}_{\mathrm{W}}$ alteration takes place, characterised by a change in the physicochemical character of the mucus secreted that initiates or contributes to a decrease in clearance of the mucus. Initially, this mucus has very low $\stackrel{\mathbb{D}}{\rightarrow}$ viscoelasticity and it contains a ciliary inhibiting fac- 0 tor. Such mucus may interact in some as yet 0 unknown fashion with other factors responsible for the exudation and bronchoconstriction characteris- 
tic of the asthmatic exacerbation. Clinically, the "benign" gross appearance of this watery sputum may be deceptive since persistent impairment of mucociliary clearance can easily lead to stagnation of the secretion, converting the slurry mucus to the hard intra-airway plugs characteristic of advanced stages of clinical asthma. Elucidation of the exact nature of the ciliary inhibitory factor found in the secretions of asthmatic patients would form an important link in understanding of the pathogenesis of the asthmatic process. Hitherto most of the emphasis has been directed towards explaining the mechanisms leading to bronchoconstriction and bronchial congestion or oedema. It is now apparent that the production of a specific secretion into the bronchial lumen could carry important pathogenetic implications.

We wish to thank Oscar J Wooten for expert technical assistance, and Dr Kenneth B Adler of the department of pathology, University of Vermont, for the electron microscopic studies. The study was supported by the Medical Research Service of the Veterans Administration.

\section{References}

${ }^{1}$ Spock AH, Heick MC, Cress H, Logan WC. Abnormal serum factor in patients with cystic fibrosis of the pancreas. Pediatr Res 1967;1:173-7.

${ }^{2}$ Conover JH, Bonforte RJ, Hathaway P, Paciuc S, Conod EJ, Hirschhorn K, Kopel FB. Studies on ciliary dyskinesia factor in cystic fibrosis. Bioassay and heterozygote detection in serum. Pediatr Res 1973;7:220-3.

${ }^{3}$ Wilson GB, Fudenberg HH. Ciliary dyskinesia factors in cystic fibrosis and asthma. Nature 1977;266:463-4.

${ }^{4}$ Bowman BH, Lockhart LH, McCombs ML. Oyster ciliary inhibition by cystic fibrosis factor. Science 1969;164:325-6.

s Bowman BH, Lankford BJ, McNeely MC, Carson SD, Barnett DR, Berg K. Cystic fibrosis: studies with the oyster ciliary assay. Clin Genet 1977;12:333-43.

${ }^{\circ}$ Cherry JD, Roden VJ, Rejent AJ, Dorner RW. The inhibition of ciliary activity in tracheal organ cultures by sera from children with cystic fibrosis and control subjects. J Pediatr 1971;79:937-42.

${ }^{7}$ Verdugo P, Hinds TR, Vincenzi FF. Laser lightscattering spectroscopy: preliminary results on bioassay of cystic fibrosis factor(s). Pediatr Res 1979;13:131-5.

${ }^{8}$ Kennedy JR, Lin KTD, Duckett K. Serum complement
( $C^{\prime} 3 a$ and $C^{\prime} 5$ ) induced inhibition of rabbit tracheal cilia. Cell Motility 1982; suppl 1:71-5.

${ }^{9}$ Frigas E, Loegering DA, Solley GO, Farrow GM, Gleich GJ. Elevated levels of the eosinophile granule major basic protein in the sputum of patients with bronchial asthma. Mayo Clin Proc 1981;56:345-53.

${ }^{10}$ Frigas E, Loegering DA, Gleich GJ. Cytotoxic effects of the guinea pig eosinophile major basic protein on tracheal epithelium. Lab Invest 1980;42:35-43.

"Chen TM, Dulfano MJ. Ciliary inhibitory factor in sputum of asthmatic patients. Biorheology 1978;15:459 (abstract).

${ }^{2}$ Dulfano MJ, Luk CK, Beckage M, Wooten O. Ciliary inhibitory effects of asthma patients' sputum. Clin Sci 1982;63:393-6.

${ }^{13}$ Yager J, Chen TM, Dulfano MJ. Measurement of frequency of ciliary beats of human respiratory epithelium. Chest 1978;73:627-33.

${ }_{14}$ American Thoracic Society. Definitions and classification of chronic bronchitis, asthma and pulmonary emphysema. Am Rev Respir Dis 1962;85:762-8.

${ }^{15}$ Dulfano MJ. Bronchial mucus-role in acute asthma. Allergy and Clinical Immunology (Excerpta Medica International Congress Series) 1976;414:285-93.

${ }^{16}$ Holma B, Lindegren M, Andersen JM. pH effects on ciliomotility and morphology of respiratory mucosa. Arch Environ Health 1977;32:216-26.

${ }^{17}$ Dulfano MJ, Luk CK, Beckage M, Wooten O. Ciliary beat frequency in human respiratory explants. Am Rev Respir Dis 1981;123:139-40.

${ }^{18}$ Luk CK, Dulfano MJ. Effect of $\mathrm{pH}$, viscosity and ionic strength changes on ciliary beating frequency of human bronchial explants. Am Rev Respir Dis 1982;125, suppl: 244 (abstract).

19 Turiaf J, Rose Y, Basset G, Liozen F. Lesions of the bronchial mucosa in asthma-like disorders: spasmodic, coriza, laryngotracheitis and eosinophilic bronchorrhea. Bull Mem Soc Med Hôp Paris 1958; 74:676-9.

${ }^{20} \mathrm{Keal}$ EE, Reid L. Pathologic alterations in mucus in asthma within and without the cell. In: Stein M, ed. New directions in asthma. Vol III. Chicago: ACCP, 1975:233-9.

2' Santa Cruz R, Landa J, Hirsch J, Sackner MA. Tracheal mucous velocity in normal man and patients with obstructive lung disease. Effects of terbutaline. Am Rev Respir Dis 1974;109:458-63.

${ }^{22}$ Mossberg B, Strandberg K, Philipson .K, Camner P. Tracheobronchial clearance in bronchial asthma; response to beta-adrenoceptor stimulation. Scand J Respir Dis 1976;57:119-28.

${ }^{23}$ Chen TM, Dulfano MJ. Mucus viscoelasticity and mucociliary transport rate. J Lab Clin Med 1978;91:423-31. 


\section{Notices}

Course on respiratory medicine: applied pharmacology and treatment

A course on applied pharmacology and treatment in respiratory medicine will be held at the Royal Postgraduate Medical School from Monday 25 April to Friday lunchtime 29 April 1983. The course is intended for those with a strong interest in respiratory medicine who want an update on treatment. The fee (including catering) is $£ 100$ for home students and members of the EEC and $£ 375$ for overseas students. Application forms and provisional programme from the School Office (SSC), Royal Postgraduate Medical School, Hammersmith Hospital, Du Cane Road, London W12 0HS (01-743 2030 ext 351).

\section{Fourth World Congress on Bronchoesophagology}

The Fourth World Congress on Bronchoesophagology, arranged by the International Bronchoesophagological Society, the Swedish Otolaryngological Society, and the
Swedish Society for Pulmonary Diseases, will be held at the Foresta Conference Center, Stockholm, on 20-23 June 1983. The programme will include sessions on biopsy methods, diagnosis, management, anaesthesia, laryngotracheal injuries, bronchopulmonary complications of gastroesophageal disorders, and mucociliary activity in obstructive lung disease, and also free communication papers and an exhibition. Further information from IBES Congress 1983, c/o RESO Congress Service, S-105 24 Stockholm, Sweden (tel +46820 1662; telex 17639 (Resohbc s); cable Folkreso).

\section{Correction}

Sputum and ciliary inhibition in asthma

In the paper by Drs MJ Dulfano and CKA Luk (September, pp 646-51) "white blood" should be deleted at the end of the last footnote to table 1. 